\title{
Social Identity and Health: An Intergroup Communication Approach to Cancer
}

\author{
Jake Harwood \\ Department of Communication \\ University of Arizona \\ Lisa Sparks \\ Department of Communication \\ George Mason University
}

\begin{abstract}
This article describes the ways in which group identifications and stereotypes can inform our understanding of cancer prevention and treatment as well as more general social processes surrounding the experience of cancer. From a perspective grounded in social identity theory, we describe the ways in which understanding primary identities (i.e., those associated with large social collectives such as cultural groups), secondary identities (i.e., those associated with health behaviors), and tertiary identities (i.e., those associated with cancer) can help explain certain cancer-related social processes. We forward a series of propositions to stimulate further research on this topic.
\end{abstract}

This article examines the role of social group memberships in health communication. Much work has focused on the ways in which individuals are influenced by their group memberships. People orient to one another in terms of not only individual characteristics but also group identifications. This occurs in terms of individuals' perceptions of their own groups (social identities), and their perceptions of others' group memberships (e.g., stereotypes). Identities and stereotypes influence how we communicate with others. We term this an intergroup approach, grounded in the pioneering work of Tajfel (Robinson, 1996; Tajfel \& Turner, 1986). We contend that intergroup processes are relevant to health communication. Although

Request for reprints should be sent to Jake Harwood, Department of Communication, University of Arizona, Tucson, AZ 85721. E-mail: jharwood@u.arizona.edu 
previous work has touched on these processes, it has not provided an integrative intergroup theoretical framework. We suggest three levels of identity to be considered in establishing a meaningful agenda for intergroup work on cancer. First, the identities that have traditionally been at the center of intergroup research need to receive attention (identification with large social groups such as cultures or nationalities, sex groups, age groups, and the like). Second, we need to attend to identities associated with health-related behaviors. The most obvious of these is identification as a smoker, but there are others, including some with more positive connotations (e.g., identification as a runner). Third, we must attend to identities that are unique to those who have cancer. Identification as a sick person, identification as a cancer patient or victim, and identification as a survivor are all pertinent here. In this article we provide some context regarding communication issues in the cancer context. Following this, we describe how examining processes at each level of identity will aid our understanding of health outcomes. Propositions surrounding each level are identified. At the outset we should define group identification. Individuals who identify with a group are those who see their group membership as central to who they are, who are proud of their group membership, and who act in terms of their group membership. Measurement instruments exist to tap this construct (e.g., Garstka, Branscombe, \& Hummert, 2001). Identification is also indicated by specific behaviors (e.g., members of the NAACP generally have higher levels of African American identification than similar nonmembers).

\section{COMMUNICATION AND CANCER}

In the provider-patient consultation, discussion of cancer evokes strong responses in patients and their family members. Once diagnosed, patient and family are inundated with opinions, visits to cancer centers, reading and information gathering, and discussions among friends. These may result in distorted interpretations of physician-patient consultations or hostility toward providers. Patients and family members operate from an emotional mixture of anger and numbing fear. Health care providers other than oncologists are often the first to discover the cancer and have to cope with communicating the news to fearful and angry patients (Ong et al., 1998).

Investigations of provider-patient communication following cancer diagnosis are infrequent relative to other research. Theory-driven research is needed in areas such as hospital and physician check-ups, survivorship, quality of life, and hospice care as well as family processes such as care, bereavement, and grief. Most cancer patients experience surgery and rounds of chemotherapy or radiation over long periods of time. Although some care may be provided by nurses and physician assistants, physician communication of information and support is as important. Patients and their family members rely on health providers for emotionally 
appropriate support and accurate information. Social and behavioral scientists find consistent relations between quality physician-patient communication and positive health outcomes (Kreps \& O'Hair, 1995).

Cancer is probabilistically associated with certain group memberships. For instance, it is the second leading cause of death in the United States for those 65 and over (National Center for Health Statistics, 2000), with about $55 \%$ of cancer cases occurring in that group - a number that is growing (Nordin et al., 2001; Walker, Kohler, Heys, \& Eremin, 1998). Older adults diagnosed with cancer are at increased risk for poor communication with health professionals (Adelman \& Greene, 2000; Greene \& Adelman, 2001). Although there is some indication that older patients prefer a less active role in medical decision making (Arora \& McHorney, 2000; Kaplan, Gandek, Greenfield, Rogers, \& Ware, 1995), physicians must ascertain patients' desire for involvement in treatment decisions (Maguire, 1998) as well as their levels of health literacy (Gazmararian et al., 1999) in order to provide adequate understanding of health messages and the ability to care for medical problems. Problems associated with caring for a cancer patient may be exacerbated if the patient, the caregiver, or both are elderly, and physicians should be open to discussions about home care and assistance with daily tasks.

Little is known about the nature of communication in medical specialties outside of primary care; however, the National Cancer Institute has focused research on oncology in recent years. Studies on the delivery of bad news, truth telling, informed consent, and end of life interactions have elucidated the dynamics of provider-patient interactions internationally (e.g., Ford, Fallowfield, \& Lewis, 1996; Kruijver, Kerkstra, Bensing, \& van de Wiel, 2001; Ong, Visser, Lammes, \& de Haes, 2000; Siminoff, Ravdin, Colabianchi, \& Sturm, 2000; Takayama, Yamazaki, $\&$ Katsumata, 2001). Ong et al. (1998) found that oncologists were more verbally dominant, informative, attentive, and expressive of concern to patients than were general practitioners. Ford et al. (1996) found that cancer patients who received bad news were given much information, reassurance, and counseling from their physicians about biomedical topics but little attention concerning psychological, social, and emotional adjustment to cancer. Patients report significantly higher satisfaction when physicians' communication is positive in tone (Ong et al., 2000), when the oncologist uses open-ended probes allowing more patient input (Takayama et al., 2001), and when the physician is not verbally dominant (Siminoff et al., 2000). The remainder of the article discusses the three levels of identity that were described at the outset.

\section{Primary Identities}

Most work in intergroup communication and social psychology has examined identities stemming from large social groups, for example, ethnic identity (Branscombe, Schmitt, \& Harvey, 1999; Hecht, 1993) and age identity (Harwood, 
Giles, \& Ryan, 1995). This research has provided suggestive evidence for the propositions that follow.

Discrimination as a result of group membership can cause stress that has health consequences. Stress may influence the trajectory of cancer, perhaps via effects on the immune system (Eysenck, 1994, 1995). Debates about the direct causal role of stress in cancer are ongoing (McGee, 1999) and more contentious than the role of stress in cardiovascular disease (Creagan, 1997). However, even if direct effects of stress are small, stress can indirectly influence the development of cancer (e.g., via effects on smoking) and the ability to cope with a cancer diagnosis (Grossarth et al., 2000). It is clear that perceived discrimination causes stress (Williams \& House, 1991; Williams, Spencer, \& Jackson, 1999), and discrimination-related stress has been linked to a number of health problems (Williams et al., 1999). Indeed, poorer health among members of minority communities, and particularly African Americans, has been explained in this way (National Center for Health Statistics, 1994). The physiological responses to discrimination are similar to those of other stressors (Anderson, 1989; Dion, Dion, \& Pak, 1992). An intergroup perspective grounded in social identity theory provides an explanation for the origins of discriminatory behaviors and hence helps us understand the origins of some of these health differentials. Discrimination is a fundamentally communicative phenomenon-individuals experience discrimination in the course of interpersonal interactions (Ruscher, 2001). For instance, patronizing communication may reveal others' age stereotypes (Hummert \& Ryan, 2001), or nonverbal cues may indicate racial prejudice (Word, Zanna, \& Cooper, 1974). Prejudice may be expressed in largely unconscious linguistic processes (Maass, Salvi, Arcuri, \& Semin, 1989) or blatant hate speech (Leets, 2001).

As an extension to this proposition, a number of cognitive processes moderate the stressful effects of discrimination. Levels of group identification buffer the relation between discrimination and health. Group identity is a psychosocial resource on which individuals can draw when dealing with discrimination or disease (Phinney, 1990). Hence, the extent to which African Americans felt close to and embedded in their ethnic group buffered the relation between perceived discrimination and health (Crocker \& Major, 1989; Williams et al., 1999). Group identification may provide similar social support resources as a close personal relationship (Contrada \& Ashmore, 1999). Attributions for discrimination are also important. For some, negative events may be attributed to situational factors. For others, they may be attributed to widespread patterns of discrimination. Individuals in the latter condition may suffer negative consequences (e.g., perceiving discrimination to be an enduring aspect of their social environment; Branscombe et al., 1999). However, high identifiers do not suffer the same degree of negative consequences from the perception of discrimination as low identifiers (Branscombe et al., 1999). High identifiers are also more likely to engage in action designed to 
counter discrimination (e.g., various forms of social activism; Tajfel \& Turner, 1986). Such assertive responses to discrimination may buffer negative effects of discrimination, compared to individuals who respond passively (Krieger, 1990). A final note is worthwhile here. Cole, Kemeny, Taylor, and Visscher (1996) found that homosexuals who hide their sexuality are at higher risk of cancer (and other health problems). Hence, for identities that are optionally disclosable, it seems that the stresses involved in closeting the identity may have negative health consequences. Cole et al. relate their findings to the health consequences of psychological inhibition. Inhibition concerning an important social identity is related to negative health consequences, even when numerous other relevant variables are controlled. Tajfel's work, while not explicitly addressing health issues, does point to other negative consequences of concealing group identity ("passing," or in social identity theory terms, "social mobility"; Tajfel \& Turner, 1986).

Stereotypes of social groups can influence diagnosis and treatment. A second way in which group memberships may link to health outcomes is in terms of diagnosis and treatment issues. Physicians may stereotype their patients, diagnosing or treating medical complaints in ways that fit cognitive schemas of the patients' group memberships (Fitzpatrick \& Vangelisti, 2001). Hence, individuals from particular groups may be underdiagnosed, or undertreated, compared to those from other groups. This effect has been noted particularly with older adults, whose symptoms are treated as a "normal" part of old age, as opposed to being treated in a way that would be routine for younger patients (Hamel et al., 2000; Rayburn \& Stonecypher, 1996; Uncapher \& Arean, 2000). The way in which information seeking can be driven by stereotypes has been documented ( $\mathrm{Ng}$, Giles, $\&$ Moody, 1991). Hence, further attention to the role of stereotypes in doctor-patient encounters is warranted (Greene \& Adelman, 2001). Indeed, harmful consequences of stereotyping may extend to the family context. For instance, Noone, Crowe, Pillay, and O'Keeffe (2000) found that relatives underestimate the extent to which older people wish to be informed of a cancer diagnosis.

\section{Identification will influence awareness of links between social group mem-} bership and illness as well as preventive and treatment practices. Group identification will influence awareness of disease predispositions and preventive and treatment practices. In terms of awareness, we would predict that when there are links between a particular disease and group membership, awareness of the disease and its risks would be greater for those who are high identifiers with the group. This would apply to situations where the relationship is probabilistic (e.g., for African Americans, the predisposition to sickle cell cancer is higher than for other groups, but anyone can suffer from sickle cell disease) or definitive (e.g., cervical cancer is uniquely a women's disease). Hence, we would expect African Americans who identify more strongly with their ethnic group to be more aware of 
sickle cell disease and more strongly identified women to be more aware of cervical cancer. From this, we might predict that more highly group-identified individuals would be more likely to engage in appropriate preventive practices (e.g., regular pap smears for highly identified women, screenings for age-related cancers such as colorectal cancer among more highly identified older adults). These individuals might also be expected to talk more about risks and treatment options among their peers. Put differently, individuals who are ambivalent or who disidentify with their group will be less likely to engage in these behaviors and likely to be aware of specific group-related risks.

The situation can get more complicated than this. For instance, men have been shown to be less likely to seek medical care and engage in preventive actions than women, and this reluctance appears to be tied to identity issues ("Real men don't need help!"; Gascoigne, Mason, \& Roberts, 1999). Hence, for “men's" cancers, predicting behavior is more complex. Highly identified men might be reluctant to engage in appropriate behaviors due to the independent or self-sufficient aspects of that identification. So self-exams for testicular cancer, for instance, might not be expected to follow the pattern described previously, or highly identified men might be less likely to seek treatment. More theoretical and empirical work will be necessary to tease apart such complex issues (Herd \& Grube, 1996; Morman, 2000). Finally, group identification may influence cancer risk when identification is tied to particular behaviors. For instance, smoking may be seen as a marker of rebellious youth identity (Pederson, Koval, \& O'Connor, 1997). More strongly identified adolescents may be more likely to smoke and suffer subsequent health problems. For other groups, not smoking may be a marker of cultural distinctiveness, and thus highly identified members of these groups may be less at risk (e.g., young African Americans; Robin, 1999). Hence, there are links here between the primary identities as members of large-scale social groups and the identities with specific behaviors as outlined in the next section.

\section{Secondary Identities}

Certain behaviors can alter the risk of cancer. An intergroup perspective leads us to examine the extent to which identification with those behaviors, or with groups that are associated with those behaviors, might influence cancer risks and outcomes. We suggest two propositions.

Individuals who feel a sense of identification with others who engage in unhealthy cancer behaviors will find it harder to change those behaviors and will be more likely to suffer negative health consequences than those who engage in the behaviors without such a sense of identification. The most prominent behavior associated with cancer risk is smoking. Smokers identify as being a "smoker" to various degrees—-that is, for many smokers this is a mean- 
ingful social category to which they belong and with which they identify (Falomir \& Invernizzi, 1999; Ogden \& Nicoll, 1997). Indeed, it is likely that various antismoking activities of recent years have contributed to this (e.g., smokers now congregate just outside doorways and interact with one another, and smokers have an increased sense of being oppressed, both of which might build group solidarity). We suggest that individuals who are highly identified as smokers are less likely to want to quit and will find it harder to quit even if they want to. They may have a higher awareness of the health risks associated with smoking (see earlier) but will also have more elaborate rationales for continuing to smoke (see Booth-Butterfield, 2003). A similar logic could be applied to other behaviors that have been found to increase the likelihood of cancer occurrence (e.g., sun exposure, dietary practices).

Individuals who feel a sense of identification with others who engage in healthy or anticancer behaviors will find it easier to maintain those behaviors and will be less likely to suffer negative health consequences than those who engage in the behaviors without such a sense of identification. The converse of the preceding argument is proposed for those who engage in healthy behaviors. Identifying as a runner, a healthy eater, or a gym rat and seeing those as important elements of self-concept are likely to lead to maintenance of those behaviors. Others who want to exercise (for instance) but do not identify with exercise as an element of their self-concept are likely to find it harder to maintain this lifestyle (the same logic would apply to regular sunscreen users or healthy chefs, for instance).

\section{Tertiary Identities}

As noted at the outset, we see it as important to attend to the ways in which individuals identify with their position as cancer patients or victims (and the precise terminology may well matter!) as well as their identification as survivors. A related area here is the extent to which they identify as members of a specific group of either patients or survivors (e.g., in the form of a support group). We suggest the following propositions.

Identification as a cancer patient will have positive consequences in terms of encouraging information seeking, social support seeking, attention to health behaviors, and compliance with medication regimens. It will have negative consequences to the extent that it encourages a sense of cancer as an intrinsic part of the self. On first diagnosis, most individuals will make efforts to understand more about their illness, uncover treatment options, and so forth. For some, this will develop into seeking information from other cancer patients and joining together with them (either in person or in virtual envi- 
ronments such as on-line chat rooms). Such joining together may well be driven in part by a growing sense of identity with the group and in a cyclical fashion will also lead to greater identification. On-line forums might be particularly associated with increased identification, given the relative anonymity and reduced opportunities for perception of individuating information (Postmes, Spears, \& Lea, 1998). As individuals identify with others with similar problems, they are likely to conform to group practices in terms of health care, knowledge, and the like (van Knippenberg, 1999). Such social pressures would be likely to have positive consequences in the current context.

In contrast to the argument in the previous paragraph, we suggest that there may be unhealthy consequences related to identification as a cancer patient. In particular, the degree to which patients identify with a "sick role" may lead to reduced feelings of control, a tendency to defer to physicians, and the like (Parsons, 1951; Charmaz, 1999). In addition, identification with being sick may override or overwhelm other important social identifications that may serve positive health functions (Charmaz, 1999). In part, the extent to which identification as a cancer patient has positive or negative consequences may well depend on the cognitive representations that are most salient with regard to the identity. Self-stereotyping research suggests that identification with a group leads to a view of the self that is in accord with a prototypical representation of the group (Levy, 1996; Reicher, 1987). If the prototypical cognitive representation of someone with cancer is of an empowered, active person successfully fighting the disease (e.g., Tour de France winner and cancer survivor Lance Armstrong), the consequences of identification are likely to be positive. However, if the prototypical cognitive representation is of an enfeebled fourth stage "terminal case," then the consequences of identification will probably be negative. More detailed understanding of cognitive representations of people with cancer would be very useful (see also subsequent discussion).

Cancer-related discrimination or stigma will be associated with cancer-related outcomes. Very little work has examined social representations (stereotypes) of cancer patients. It is clear that there is a certain stigma associated with all illness, particularly potentially terminal illness (Lester, 1992; Peters, den Boer, Kok, \& Schaalma, 1994). Hence, once an individual becomes sick with cancer, he or she may well experience discrimination, and for some individuals it may be their first experience of such treatment. Research needs to examine more about the stereotypes of cancer patients that currently exist. It seems likely, following from other research on stereotypes (e.g., Eckes, 1994; Hummert, Garstka, Shaner, \& Strahm, 1994), that multiple stereotypes of cancer patients exist (e.g., a "battling to the death" heroic stereotype, the frail young gay male). It would be useful to examine the extent to which these are shared in the population and portrayed in the media. 
Once these are uncovered, additional work should examine the ways in which communication with cancer patients is driven by such stereotypes. We need to know whether physicians or other support providers invoke such stereotypes when interacting with cancer patients. Likewise, it will be important to discover the extent to which cancer patients themselves may be self-stereotyping into such categories and whether that self-stereotyping might influence their communication with others, their health-related behaviors, and the like. In some cases this might be positive. Self-stereotyping as a "battler" might have positive consequences in terms of not giving up, trying multiple therapies, taking a proactive approach to health care, and the like.

Contact with cancer patients may reduce or modify damaging stereotypes. Research on the "contact hypothesis" has yielded a wealth of findings over the past 50 years (Allport, 1954; Pettigrew, 1998). The evidence suggests that contact with members of a stigmatized outgroup can ameliorate negative attitudes, particularly under certain conditions (e.g., contact is equal status, cooperative, pleasant; Amir, 1976; Brewer \& Miller, 1988). Most recently, work has suggested that group memberships need to be salient in such contact (Harwood, Hewstone, Paolini, \& Hurd, 2002; Hewstone \& Brown, 1986). Hence, to improve attitudes toward cancer patients in general, we should encourage contact in which the health status of patients is salient and they are seen as typical of cancer patients as a group. Such contact might lead to generalization from pleasant contact with one individual to more positive attitudes toward all cancer patients.

Identification as a survivor will have a positive influence on continued survival. In general, we see positive consequences stemming from an identification with other cancer survivors and a tendency to view the self in terms of survivorship. Identification as a survivor should link to internal locus of control and more general feelings of self-esteem (Deimling, Kahana, \& Schumacher, 1997), which are themselves associated with increased survival (Contrada, 1989). Identification with other survivors may also enhance preventive measures, such as a healthy lifestyle (Mears, 1997). Thus, it seems likely that continued involvement with support groups and even continued medical tests and the like may serve positive functions. Although there are inevitable stresses involved, medical check-ups and consultations may serve a function beyond the purely medical in reminding patients of their continued good health and success in dealing with the disease.

\section{CONCLUSIONS AND THEORETICAL DIRECTIONS}

The preceding discussion is intended to illustrate the range of important issues surrounding cancer that can be addressed by using an intergroup framework. There 
are others. For instance, chemotherapy and surgery can result in physical changes, and some cancers result in profound sociorelational impacts (e.g., the impact of prostate and testicular cancer on sexual function; Arrington, 2000; Manderson, 1999; mastectomy and gender/sexual identity: Roberts \& Cox, 1997). In this article we are more concerned with the effects of identity on health-related issues. However, research on the identity consequences of cancer is important and would fit within our framework.

The goal of this article has been to begin the discussion, provide a framework, and present some propositions emerging from prior research and theory in this area. Much work has already addressed some of these issues (e.g., discrimination-related stress and illness). In other cases, an intergroup framework suggests areas of research that appear to be relatively untapped (e.g., smokers' levels of identification with one another and the impact of antismoking regulations on that identity; the content and pervasiveness of stereotypes of cancer patients). We note that we are not the first to suggest a broadly intergroup approach to health concerns. Dryden and Giles (1987) made the point that doctor-patient encounters can be usefully contextualized as intergroup encounters for the purposes of understanding miscommunication in such contexts. Similarly, Fitzpatrick and Vangelisti's (2001) recent kaleidoscope model of health communication draws on social identity as one "level" determining the ultimate health of patients in a health encounter.

Some of the identities discussed here are on the borderlines of what are traditionally thought of as collective identities. Other identities are somewhat beyond the confines of social identity theory but are also relevant. Family identity, for instance, may be crucial among those who have family histories of particular forms of cancer. Women in a family with a history of breast cancer, for instance, are in a situation where information and awareness about the disease should be heightened, preventive measures should be relatively automatic, and knowledge about treatment options in the case of illness should be readily available. However, the extent to which those women identify with the family may be crucial. People who are less involved and identified with their family may dissociate from the medical history and perhaps perceive themselves as less vulnerable.

Identification with support groups is worth examining from this perspective, despite the fact that a specific support group is a somewhat smaller "group" than is traditionally the focus of intergroup research. Recent research on AIDS support groups has described some of the positive and negative consequences of engaging in such groups. Brashers et al. (2000) noted the stresses involved when members of the group undergo declines in health or die. An intergroup perspective would predict that such stress would be particularly powerful for those who identify most strongly with the support group. At the same time, identification with the group may serve positive functions in terms of valuing the support received, following guidance, attending regularly, and maintaining group life. This double-edged sword of support group identification is worth further examination. 
Where does this leave us, theoretically? Clearly, this article is not a theoretical statement so much as a call for theoretical development. Two paths are possible. First, it is possible to generate an identity-based theory of communication and health-related behavior. Such a theory might incorporate the propositions described here, developing and integrating them in ways that emphasize the processes common to them all. A second route would be to incorporate identity-related constructs into current theories of health communication. The health belief model might be expanded to include a number of the intergroup phenomena outlined in this article (Chew, Palmer, \& Kim, 1998; Sheeran \& Abraham, 1996). For example (and this is just one example), the concept of efficacy is central to the health belief model. Examinations of the role of group identification in influencing efficacy processes would reveal ways in which identity might be integrated within the health belief model. Strong levels of "smoker identification" might be a powerful influence on efficacy in terms of quitting. Highly identified smokers might view their chances of being able to quit as lower than those who do not so identify, even among individuals who smoke similar amounts. Once such links are understood, programs designed to reduce identification with smoking and other smokers and to increase identification with other groups might have a profound effect on efficacy and might increase the ability to quit. Pechmann (2001) noted the ways in which emphasizing negative stereotypes associated with groups such as smokers might influence a shift away from smoking and perhaps toward other (more healthy) identities. Our intergroup perspective would embrace such research and offer new resources. For example, intergroup theory makes it clear that abandoning a particular identity is possible for the weakly identified. For the more strongly identified, a strategy like that described by Pechmann may result in enhanced identification and social activism (e.g., for "smokers' rights"!) to combat the perceived identity threat.

\section{REFERENCES}

Adelman, R., \& Greene, M. (2000). Communication between older patients and their physicians. Clinics in Geriatric Medicine, 16, 1-24.

Allport, G. W. (1954). The nature of prejudice. Reading, MA: Addison-Wesley.

Amir, Y. (1976). The role of intergroup contact in change of prejudice and race relations. In P. A. Katz (Ed.), Toward the elimination of prejudice (pp. 245-280). New York: Pergamon.

Anderson, N. B. (1989). Racial differences in stress-induced cardiovascular reactivity and hypertension: Current status and substantive issues. Psychological Bulletin, 105, 89-105.

Arora, N., \& McHorney, C. (2000). Patient preferences for medical decision making. Medical Care, 38, 335-341.

Arrington, M. (2000). Thinking inside the box: On identity, sexuality, prostate cancer, and social support. Journal of Aging and Identity, 5, 151-158.

Booth-Butterfield, M. (2003). Embedded health behaviors from adolescence to adulthood: The impact of tobacco. Health Communication, 15, 2, 173-186. 
Branscombe, N. R., Schmitt, M. T., \& Harvey, R. D. (1999). Perceiving pervasive discrimination among African Americans: Implications for group identification and well-being. Journal of Personality and Social Psychology, 77, 135-149.

Brashers, D. E., Neidig, J. L., Haas, S. M., Dobbs, L. K., Cardillo, L. W., \& Russell, J. A. (2000). Communication in the management of uncertainty: The case of persons living with HIV or AIDS. Communication Monographs, 67, 63-84.

Brewer, M. B., \& Miller, N. (1988). Contact and cooperation: When do they work? In P. A. Katz \& D. A. Taylor (Eds.), Eliminating racism (pp. 315-326). New York: Plenum.

Charmaz, K. (1999). From the "sick role" to stories of self: Understanding the self in illness. In R. J. Contrada \& R. D. Ashmore (Eds.), Self, social identity, and physical health: Interdisciplinary explorations (pp. 209-239). New York: Oxford University Press.

Chew, F., Palmer, S., \& Kim, S. (1998). Testing the influence of the health belief model and a television program on nutrition behavior. Health Communication, 10, 227-245.

Cole, S. W., Kemeny, M. E., Taylor, S. E., \& Visscher, B. R. (1996). Elevated physical health risk among gay men who conceal their homosexual identity. Health Psychology, 15, 243-251.

Contrada, R. J. (1989). Type A behavior, personality hardiness, and cardiovascular responses to stress. Journal of Personality \& Social Psychology, 57, 895-903.

Contrada, R. J., \& Ashmore, R. D. (1999). Introduction: Self and social identity: Key to understanding social and behavioral aspects of physical health and disease? In R. J. Contrada \& R. D. Ashmore (Eds.), Self, social identity, and physical health: Interdisciplinary explorations (pp. 3-21). New York: Oxford University Press.

Creagan, E. T. (1997). Attitude and disposition: Do they make a difference in cancer survival? Mayo Clinic Proceedings, 72, 160-164.

Crocker, J., \& Major, B. (1989). Social stigma and self-esteem: The self-protective properties of stigma. Psychological Review, 96, 608-630.

Deimling, G., Kahana, B., \& Schumacher, J. (1997). Life threatening illness: The transition from victim to survivor. Journal of Aging and Identity, 2, 165-186.

Dion, K. L., Dion, K. K., \& Pak, A. W. (1992). Personality-based hardiness as a buffer for discrimination-related stress in members of Toronto's Chinese community. Canadian Journal of Behavioral Science, 24, 517-536.

Dryden, C., \& Giles, H. (1987). Language, social identity, and health. In H. Beloff \& A. M. Coleman (Eds.), Psychology survey (pp. 115-138). Leicester, England: British Psychological Society.

Eckes, T. (1994). Explorations in gender cognition: Content and structure of female and male subtypes. Social Cognition, 12, 37-60.

Eysenck, H. J. (1994). Cancer, personality and stress: Prediction and prevention. Advances in Behaviour Research and Therapy, 16, 167-215.

Eysenck, H. J. (1995). The causal role of stress and personality in the aetiology of cancer and coronary heart disease. In C. D. Spielberger \& I. G. Sarason (Eds.), Stress and emotion: Anxiety, anger and curiosity (pp. 3-12). Philadelphia: Taylor \& Francis.

Falomir, J. M., \& Invernizzi, F. (1999). The role of social influence and smoker identity in resistance to smoking cessation. Swiss Journal of Psychology, 58, 73-84.

Fitzpatrick, M. A., \& Vangelisti, A. (2001). Communication, relationships, and health. In W. P. Robinson \& H. Giles (Eds.), The new handbook of language and social psychology (pp. 505-530). Chichester, England: Wiley.

Ford, S., Fallowfield, L., \& Lewis, S. (1996). Doctor-patient interactions in oncology. Social Science and Medicine, 42, 1511-1519.

Garstka, T. A., Branscombe, N. R., \& Hummert, M. L. (2001). Age group identification in young, middle-aged, and older adults. Unpublished manuscript, Gerontology Center, University of Kansas.

Gascoigne, P., Mason, M. D., \& Roberts, E. (1999). Factors affecting presentation and delay in patients with testicular cancer: Results of a qualitative study. Psycho-Oncology, 8, 144-154. 
Gazmararian, J., Baker, D., Williams, M., Parker, R., Scott, T., Green, D., et al. (1999). Health literacy among Medicare enrollees in a managed care organization. Journal of the American Medical Association, 281, 545-551.

Greene, M. G., \& Adelman, R. D. (2001). Building the physician-older patient relationship. In M. L. Hummert \& J. F. Nussbaum (Eds.), Aging, communication, and health: Linking research and practice for successful aging (pp. 101-120). Mahwah, NJ: Lawrence Erlbaum Associates, Inc.

Grossarth, M. R., Eysenck, H. J., Boyle, G. J., Heep, J., Costa, S. D., \& Diel, I. J. (2000). Interaction of psychosocial and physical risk factors in the causation of mammary cancer and its prevention through psychological methods of treatment. Journal of Clinical Psychology, 56, 33-50.

Hamel, M. B., Lynn, J., Teno, J. M., Covinsky, K. E., Wu, A. W., Galanos, A., et al. (2000). Age-related differences in care preferences, treatment decisions, and clinical outcomes of seriously ill hospitalized adults: Lessons from SUPPORT. Journal of the American Geriatrics Society, 48, S176-S182.

Harwood, J., Giles, H., \& Ryan, E. B. (1995). Aging, communication, and intergroup theory: Social identity and intergenerational communication. In J. F. Nussbaum \& J. Coupland (Eds.), Handbook of communication and aging research (pp. 133-159). Hillsdale, NJ: Lawrence Erlbaum Associates, Inc.

Harwood, J., Hewstone, M., Paolini, S., \& Hurd, R. (2002). Grandparent-grandchild contact and attitudes towards older adults: Moderator and mediator effects. Unpublished manuscript, University of Arizona.

Hecht, M. L. (1993). 2002—A research odyssey: Toward the development of a communication theory of identity. Communication Monographs, 60, 76-82.

Herd, D., \& Grube, J. (1996). Black identity and drinking in the U.S.: A national study. Addiction, 91, $845-857$.

Hewstone, M., \& Brown, R. J. (1986). Contact is not enough: An intergroup perspective on the contact hypothesis. In M. Hewstone \& R. J. Brown (Eds.), Contact and conflict in intergroup encounters (pp. 1-44). Oxford, England: Blackwell.

Hummert, M. L., Garstka, T. A., Shaner, J. L., \& Strahm, S. (1994). Stereotypes of the elderly held by the young, middle aged, and elderly adults. Journal of Gerontology: Psychological Sciences, 49, 240-249.

Hummert, M. L., \& Ryan, E. B. (2001). Patronizing. In W. P. Robinson \& H. Giles (Eds.), Handbook of language and social psychology (pp. 253-270). Chichester, England: Wiley.

Kaplan, S., Gandek, B., Greenfield, S., Rogers, W., \& Ware, J. (1995). Patient and visit characteristics related to physicians' participatory decision-making style. Medical Care, 33, 1176-1187.

Kreps, G., \& O'Hair, D. (Eds.). (1995). Communication and health outcomes. Norwood, NJ: Hampton.

Krieger, N. (1990). Racial and gender discrimination: Risk factors for high blood pressure? Social Science and Medicine, 30, 1273-1281.

Kruijver, I. P., Kerkstra, A., Bensing, J. M., \& van de Wiel, H. B. (2001). Communication skills of nurses during interactions with simulated cancer patients. Journal of Advanced Nursing, 34, $772-779$.

Leets, L. (2001). Response to Internet hate sites: Is speech too free in cyberspace? Communication Law and Policy, 6, 287-317.

Lester, D. (1992). The stigma against dying and suicidal patients: A replication of Richard Kalish's study twenty-five years later. Omega: Journal of Death and Dying, 26, 71-75.

Levy, B. (1996). Improving memory in old age through implicit self-stereotyping. Journal of Personality and Social Psychology, 71, 1092-1107.

Maass, A., Salvi, D., Arcuri, L., \& Semin, G. (1989). Language use in intergroup contexts: The linguistic intergroup bias. Journal of Personality and Social Psychology, 57, 981-993.

Maguire, P. (1998). Breaking bad news. European Journal of Surgical Oncology, 24, 188-199.

Manderson, L. (1999). Gender, normality and the post-surgical body. Anthropology and Medicine, 6, 381-394. 
Mears, J. B. (1997). The cultural construction of breast cancer. Dissertation Abstracts International Section A: Humanities and Social Sciences, 58(6-A), 2273.

McGee, R. (1999). Does stress cause cancer? There's no good evidence of a relation between stressful events and cancer. British Medical Journal, 319, 1015-1016.

Morman, M. T. (2000). The influence of fear appeals, message design, and masculinity on men's motivation to perform the testicular self-exam. Journal of Applied Communication Research, 28, 91-116.

National Center for Health Statistics. (1994). Health, United States 1993. Hyattsville, MD: U.S. Department of Health and Human Services.

National Center for Health Statistics. (2000). Health, United States, 2000. Hyattsville, MD: U.S. Department of Health and Human Services.

Ng, S. H., Giles, H., \& Moody, J. (1991). Information-seeking triggered by age. International Journal of Aging and Human Development, 33, 269-277.

Noone, I., Crowe, M., Pillay, I., \& O'Keeffe, S. T. (2000). Telling the truth about cancer: Views of elderly patients and their relatives. Irish Medical Journal, 93, 104-105.

Nordin, A., Chinn, D., Moloney, I., Naik, R., de Barros Lopes, A., \& Monaghan, J. (2001). Do elderly cancer patients care about cure? Gynecological Oncology, 81, 447-455.

Ogden, J., \& Nicoll, M. (1997). Risk and protective factors: An integration of the epidemiological and psychological approaches to adolescent smoking. Addiction Research, 5, 367-377.

Ong, L., Visser, M., Kruyver, I., Bensing, J. M., Brink-Muinen, A., Stouthard, J., et al. (1998). The Roter Interaction Analysis System (RIAS) in oncological consultations: Psychometric properties. Psycho-Oncology, 7, 387-401.

Ong, L., Visser, M., Lammes, F., \& de Haes, J. (2000). Doctor-patient communication and cancer patients' quality of life and satisfaction. Patient Education and Counseling, 41, 145-156.

Parsons, T. (1951). The social system. Glencoe, IL: Free Press.

Pechmann, C. (2001). A comparison of health communication models: Risk learning versus stereotype priming. Media Psychology, 3, 189-210.

Pederson, L. L., Koval, J. J., \& O'Connor, K. (1997). Are psychosocial factors related to smoking in grade-6 students? Addictive Behaviors, 22, 169-181.

Peters, L., den Boer, D. J., Kok, G., \& Schaalma, H. P. (1994). Public reactions towards people with AIDS: An attributional analysis. Patient Education and Counseling, 24, 323-335.

Pettigrew, T. (1998). Intergroup contact theory. Annual Review of Psychology, 49, 65-85.

Phinney, J. S. (1990). Ethnic identity in adolescents and adults: Review of research. Psychological Bulletin, 108, 499-514.

Postmes, T., \& Spears, R. (1998). Deindividuation and antinormative behavior: A meta-analysis. Psychological Bulletin, 123, 238-259.

Postmes, T., Spears, R., \& Lea, M. (1998). Breaching or building social boundaries? SIDE effects of computer-mediated communication. Communication Research, 25, 689-715.

Rayburn, T. M., \& Stonecypher, J. F. (1996). Diagnostic differences related to age and race of involuntarily committed psychiatric patients. Psychological Reports, 79, 881-882.

Reicher, S. D. (1987). Crowd behavior as social action. In J. C. Turner, M. A. Hogg, P. J. Oakes, S. D. Reicher, \& M. S. Wetherell (Eds.), Rediscovering the social group: A self-categorization theory (pp. 171-202). Oxford, England: Blackwell.

Roberts, C. S., \& Cox, C. F. (1997). Medical and psychosocial treatment issues in breast cancer in older women. Journal of Gerontological Social Work, 28, 63-74.

Robin, M. (1999). Explanations of ethnic and gender differences in youth smoking: A multi-site, qualitative investigation. Nicotine and Tobacco Research, 1, S91-S98.

Robinson, W. P. (Ed.). (1996). Social groups and identities: Developing the legacy of Henri Tajfel. Boston: Butterworth Heinemann.

Ruscher, J. (2001). Prejudiced communication. New York: Guilford. 
Sheeran, P., \& Abraham, C. (1996). The health belief model. In M. Conner \& P. Norman (Eds.), Predicting health behaviour: Research and practice with social cognition models (pp. 23-61). Bristol, PA: Open University.

Siminoff, L. A., Ravdin, P., Colabianchi, N., \& Sturm, C. M. S. (2000). Doctor-patient communication patterns in breast cancer adjuvant therapy discussions. Health Expectations, 3, 26-36.

Tajfel, H., \& Turner, J. C. (1986). The social identity theory of intergroup behavior. In S. Worschel \& W. G. Austin (Eds.), The social psychology of intergroup relations (2nd ed., pp. 7-24). Chicago: Nelson-Hall.

Takayama, T., Yamazaki, Y., \& Katsumata, N. (2001). Relationship between outpatients' perceptions of physicians' communication styles and patients' anxiety levels in a Japanese oncology setting. Social Science and Medicine, 53, 1335-1350.

Uncapher, H., \& Arean, P. A. (2000). Physicians are less willing to treat suicidal ideation in older patients. Journal of the American Geriatrics Society, 48, 188-192.

Van Knippenberg, D. (1999). Social identity and persuasion: Reconsidering the role of group membership. In D. Abrams \& M. A. Hogg (Eds.), Social identity and social cognition (pp. 315-331). Malden, MA: Blackwell.

Walker, L., Kohler, R., Heys, S., \& Eremin, O. (1998). Psychosocial aspects of cancer in the elderly. European Journal of Surgical Oncology, 24, 375-378.

Williams, D. R., \& House, J. S. (1991). Stress, social support, control, and coping: A social epidemiologic view. In B. Badura \& I. Kickbusch (Eds.), Health promotion research: Towards a new social epidemiology (pp. 157-172). Copenhagen: World Health Organization.

Williams, D. R., Spencer, M. S., \& Jackson, J. S. (1999). Race, stress, and physical health: The role of group identity. In R. J. Contrada \& R. D. Ashmore (Eds.), Self, social identity, and physical health: Interdisciplinary explorations (pp. 71-100). New York: Oxford University Press.

Word, C. O., Zanna, M. P., \& Cooper, J. (1974). The nonverbal mediation of self-fulfilling prophecies in interracial interaction. Journal of Experimental Social Psychology, 10, 109-120. 
Copyright of Health Communication is the property of Lawrence Erlbaum Associates and its content may not be copied or emailed to multiple sites or posted to a listserv without the copyright holder's express written permission. However, users may print, download, or email articles for individual use. 